\title{
Low dose combined oral contraceptives induced thrombotic anterior wall myocardial infarction: a case report
}

\author{
Alaa Rahhal ${ }^{1 *}$, Fadi Khir ${ }^{2}$, Mohammad Adam², Amer Aljundi', Mohammed Khalil Mohsen ${ }^{3}$ and Jassim Al-Suwaidi ${ }^{3}$
}

\begin{abstract}
Background: Combined oral contraceptive pills are associated with an established risk for venous thrombosis; however, their risk for arterial thrombosis remains uncertain, especially with the development of low dose new generations of combined oral contraceptive. Arterial thrombosis is less likely to occur with the use of oral contraceptive pills in the absence of cardiovascular risk factors.

Case presentation: We report a 35-year old female with no cardiovascular risk factors who presented with thrombotic anterior wall myocardial infarction 6 months after using a third generation low dose combined oral contraceptive pills (Marvelon; ethinylestradiol $30 \mathrm{mcg}$ and desogestrel $150 \mathrm{mcg}$ ).

Conclusion: Third generation low dose combined oral contraceptives may lead to myocardial infarction in young women, even in the absence of other cardiovascular risk factors.
\end{abstract}

Keywords: Case report, Oral contraceptives, Myocardial infarction

\section{Background}

Since the development of the oral contraceptive (OC) pills, their association with an increased risk of venous thromboembolism has been well established. This risk has been decreased, although not yet eliminated, by the introduction of newer generations of oral contraceptives with reduced doses of estrogen. The risk of arterial thrombosis has been a universally feared, but not well established, adverse event of the oral contraceptives. This risk is thought to be cumulative with the association of other risk factors of arterial thrombosis [1].

In this case report, we present a young lady who was admitted to our hospital with the diagnosis of an STelevation myocardial infarction (STEMI). Apart from the use of a third generation of OC pills, she has no associated cardiovascular risk factors.

\footnotetext{
* Correspondence: arahhal1@hamad.qa

'Pharmacy Department, Heart Hospital, Hamad Medical Corporation, P.O. Box 3050, Doha, Qatar

Full list of author information is available at the end of the article
}

\section{Case presentation}

A 35-year-old female with no past medical history was admitted to the Heart Hospital in Qatar, a cardiologyspecialized facility, with typical chest pain that began $2 \mathrm{~h}$ before admission. She described the pain as a pressurelike sensation radiating to her left arm and back and was associated with sweating. She was not a smoker or alcohol consumer and reported no illicit drug use; however, laboratory confirmation was not pursued as the suspicion of drug abuse was low. She had no history of miscarriages and no family history of coronary artery disease. She was married and using a third generation low dose combined oral contraceptive, Marvelon (ethinylestradiol $30 \mathrm{mcg}$ and desogestrel $150 \mathrm{mcg}$ ), for 6 months.

Her vital signs and body mass index were within normal range, as follows: heart rate: $71 / \mathrm{min}$, blood pressure: $126 / 73 \mathrm{mmHg}$, respiratory rate: $17 / \mathrm{min}$, oxygen saturation on room air: $100 \%$, and body mass index: $23 \mathrm{Kg} / \mathrm{m} 2$. 
Upon admission, the 12-lead electrocardiogram (ECG) showed ST-segment elevation mainly in leads I and aVL in addition to minimal elevation in V2 and V3 and associated poor $\mathrm{R}$ wave progression as shown in Fig. 1. The patient's cardiac enzymes (high sensitive Troponin-T) was elevated upon admission, and it continued to rise in the first day to $8026 \mathrm{ng} / \mathrm{L}$ as demonstrated in Fig. 2.

Primary percutaneous coronary intervention (PCI) was performed and showed a big thrombus in the proximal left anterior descending (LAD) artery and an occlusion in the mid LAD. Thrombus aspiration was done, and post aspiration coronary angiography showed residual thrombus, however, TIMI II- III flow was established, as demonstrated in Fig. 3.

She was admitted to the Cardiac Intensive Care Unit (CICU) with $48 \mathrm{~h}$ of eptifibatide infusion along with dual antiplatelet agents (aspirin and clopidogrel) as a case of thrombotic anterior wall myocardial infarction. Her echocardiogram showed hypokinesia of the antero-septal area with akinesia of the apical region. Ejection fraction (EF) was estimated to be $48 \%$. Thrombophilia workup was negative, including lupus anticoagulant, protein $\mathrm{S}$ and protein C. Protein C activity was $103.5 \%$ (70-140) and protein $S$ activity was $66.5 \%$ (56-126). Autoimmune disease screening was negative, including rheumatoid factor and antinuclear antibody (ANA).

On the fifth day of admission, she had re-look coronary angiography (CAG) which showed residual thrombus again, with no change in size, as shown in Fig. 4. However, thrombus aspiration was not performed because of risk of distal embolization. Therefore, she was kept on therapeutic enoxaparin at a dose of $1 \mathrm{mg} / \mathrm{kg}$ subcutaneous twice daily until her Troponin- $\mathrm{T}$ normalized and discharged home on day 17 th of admission. The patient was seen in the follow-up clinic 2 months post discharge and was found to be asymptomatic.

\section{Discussion and conclusion}

Thrombosis, venous as well as arterial, is the most frequently occurring serious side effect of combined oral contraceptives [1]. To reduce the harmful thrombotic risks of oral contraceptives, over the past decades, the hormonal components of OC pills have been modified. The estrogen dose has been reduced from $150 \mathrm{mcg}$ to less than or equal to $30 \mathrm{mcg}$, and new generations of progestin hormone were developed [2]. Combined oral contraceptives in the 1960s contained a first-generation progestin (norethisterone, lynestrenol), then in the 1970s, the second generation (levonorgestrel, norgestrel) was used, and in the 1980s and 1990s, the third generation (desogestrel, gestodene) started to be used in order to reduce the androgenic side effects [3-5].

The association between oral contraceptives and venous thrombosis is well established with an estimated risk of three to six folds increase compared to non-OC users [1]. Nevertheless, the association of oral contraceptives with arterial thrombosis, including myocardial infarction (MI), is controversial and not yet well-established. A recent Cochrane meta-analysis of 24 studies showed that oral contraceptives increased the risk of arterial thrombosis, including MI or ischemic stroke by 1.6 folds; MI (Relative Risk [RR] 1.6, 95\% CI 1.2 to 2.1 ) and ischemic stroke (RR 1.7, 95\% CI 1.5 to 1.9). Interestingly, the risk of arterial thrombosis did not vary among the different progestin generations; however, the relative risk increased with increasing the estrogen dose. For preparations containing $20 \mathrm{mcg}$ of estrogen the relative risk is 1.6 (95\% CI 1.4 to 1.8$)$, for preparations containing 30 to

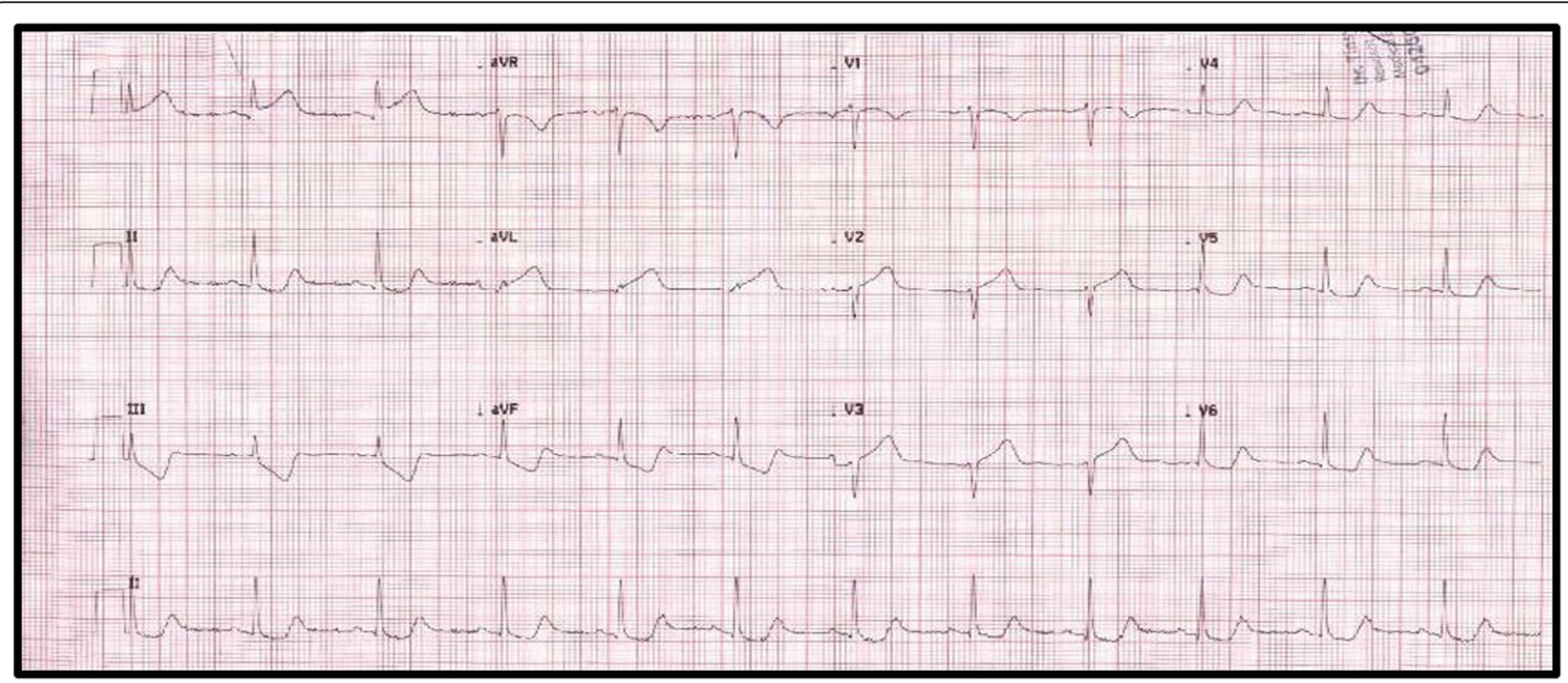

Fig. 1 Electrocardiographic features of acute anterior wall myocardial infarction at presentation 


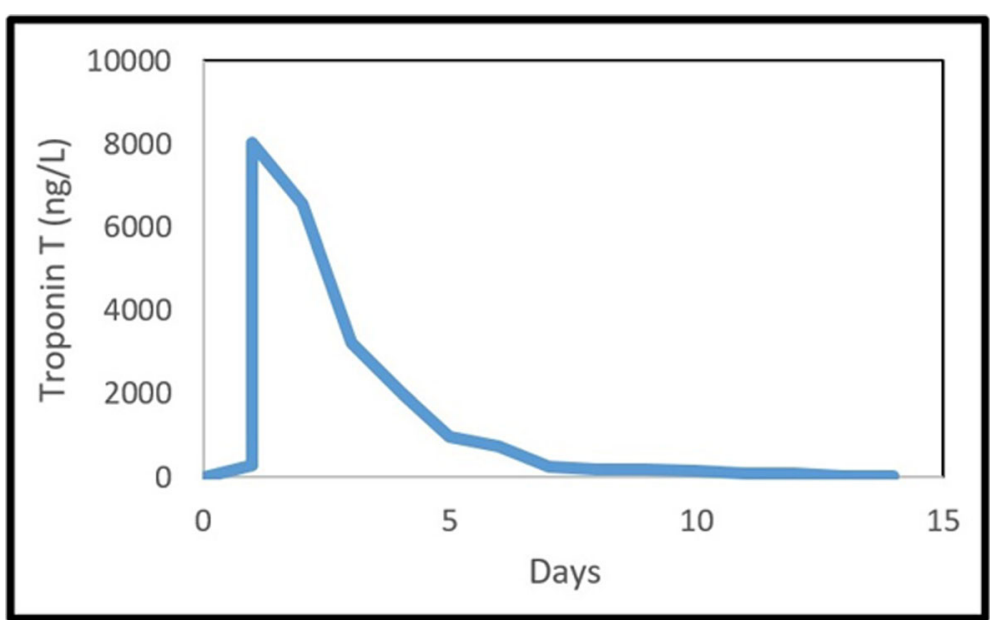

Fig. 2 High sensitive Troponin T trend during hospitalization

$49 \mathrm{mcg}$ of estrogen the relative risk is 2.0 (95\% CI 1.4 to 3.0 ), and for preparations containing $>50 \mathrm{mcg}$ of estrogen, the relative risk increases to 2.4 (CI 1.8 to 3.3) [6]. However, the risk of arterial thrombosis in relation to oral contraceptives (RATIO) study demonstrated that risk of MI associated with oral contraceptives is 2 (95\% CI 1.5-2.8) and the risk was reduced with the third generation of progestin with an adjusted odds ratio of 1.3 (95\% CI 0.7-2.5) [7].
The risk of oral contraceptive induced arterial thrombosis is more pronounced with other risk factors for arterial thrombosis; including smoking, hypertension, diabetes, and hypercholesterolemia [1]. It was shown that the risk of MI increased to 13.6-fold (95\% CI 7.923.4) for OC users with smoking history, 6.1-fold (95\% CI 3.1-12.1) for OC users with hypertension, 17.4-fold (95\% CI 3.1-98.1) for OC users with diabetes, and 24.7fold (95\% CI 5.6-108) for OC users with dyslipidemia
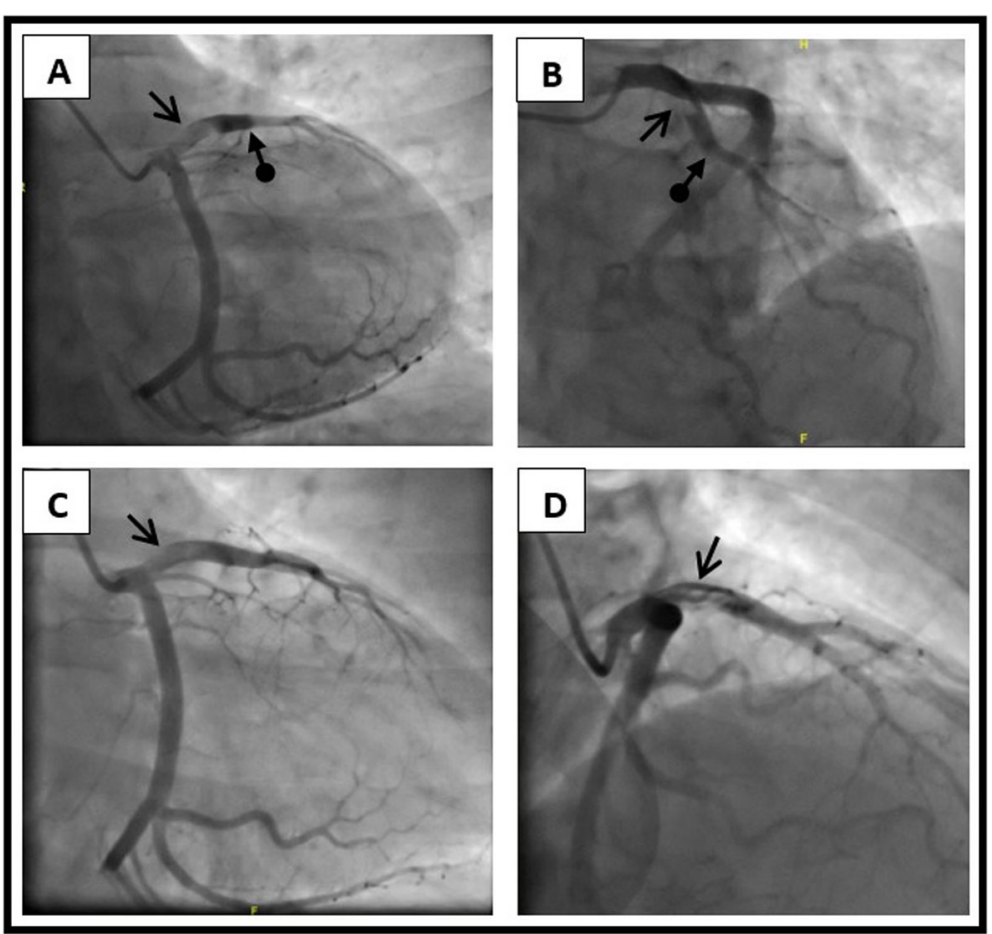

Fig. 3 a and $\mathbf{b}$ : Angiographic imaging of the proximal $L A D$ thrombus and mid LAD occlusion before thrombus aspiration in the right caudal oblique projection and left cranial oblique projection; respectively. $\mathbf{c}$ and $\mathbf{d}$ : Angiographic imaging of $L A D$ after thrombus aspiration in the right caudal oblique projection and right cranial oblique projection; respectively 


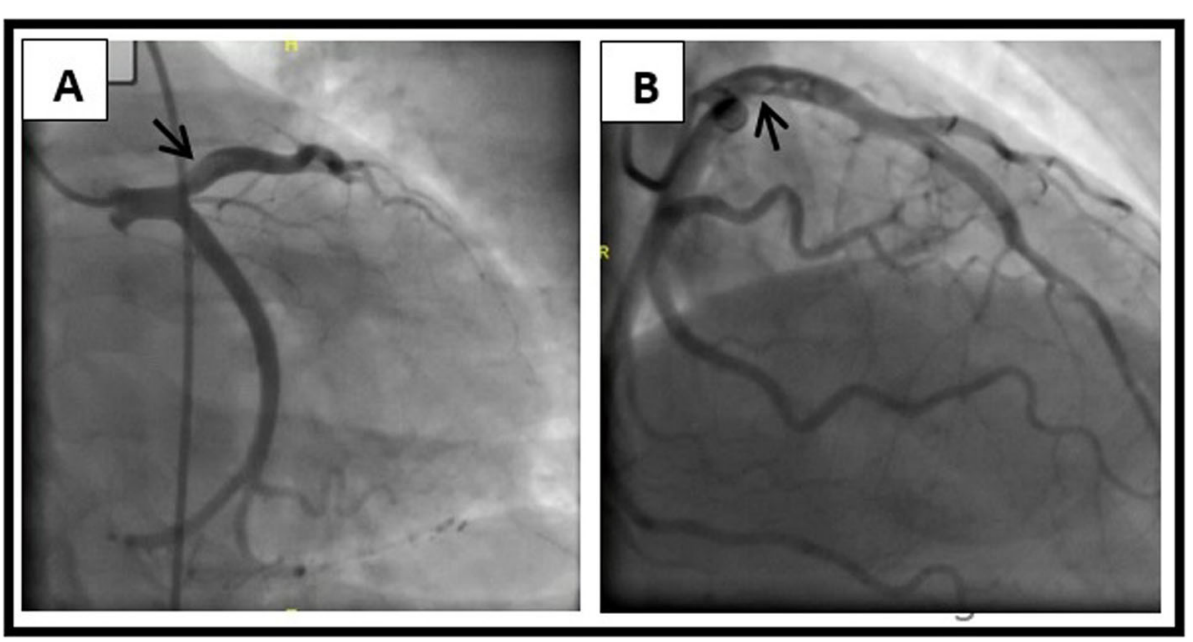

Fig. 4 a and b: Angiographic imaging of the residual thrombus at proximal LAD in the right caudal projection and right cranial oblique projection; respectively

[7]. Age is a strong risk factor for thrombosis; however, it was shown that the risk of MI induced by oral contraceptives is more common in smoking women over 35 years of age [8]. Although, the mechanism of oral contraceptives induced MI is not well understood, the cause of MI among OC users is thrombotic rather than atherosclerotic and could be attributed to the pro-thrombotic effects of oral contraceptives [8]. Oral contraceptives are associated with increased coagulation factors, including factor VII, VIII, and X along with increased activity of the fibrinolytic inhibitors; Plasminogen Activator Inhibitor (PAI)-1 and PAI-2 and decreased levels of the natural anticoagulants; antithrombin and protein $S[9,10]$.

We reported a 35-year old lady who presented with anterior wall MI and was using a third generation low dose combined oral contraceptive for 6 months. She did not have any risk factors for coronary artery disease, including hypertension, diabetes, dyslipidemia, smoking, obesity, or family history for cardiovascular diseases. No hypercoagulable disorders or auto-immune diseases were identified.

To our knowledge, this is the second case report of low dose third generation oral contraceptives induced arterial thrombosis in the absence of risk factors for MI. Aslan AN et al. reported a case of a 20-year old female, non-smoker and with no risk factors for cardiovascular disease, who developed an inferior wall MI 1 month after the use of third generation low dose oral contraceptives [11]. Compared to that case, our patient was slightly older and had been using oral contraception for a longer period. Moreover, our patient developed anterior wall MI, while in the previously reported case, the patient presented with inferior wall MI. In our case, Thrombophilia and autoimmune workup was negative; however, this was not addressed in the above-mentioned case.
In conclusion, arterial thrombotic events such as myocardial infarction can occur among patients taking third generation combined oral contraceptive pills, even in the absence of risk factors for arterial thrombosis. With the widespread use of $\mathrm{OC}$ pills, we believe that physicians should keep this risk in mind when prescribing oral contraceptives.

\section{Abbreviations}

OCP: Oral contraceptives; STEMI: ST-elevation myocardial infarction; ECG: Electrocardiogram; PCI: Percutaneous coronary intervention; LAD: Left anterior descending; CICU: Cardiac intensive care unit; EF: Ejection fraction; ANA: Antinuclear antibody; CAG: Coronary angiography; RR: Relative risk

\section{Acknowledgements \\ Not applicable.}

\section{Authors' contributions}

$A R$, FK, and MA took the lead in manuscript writing. AR, FK, MA, AA, MM, and JA participated in revising the manuscript. All authors have read and approved the final manuscript.

\section{Funding}

This case report was not supported by any funding body.

\section{Availability of data and materials}

The datasets used and/or analyzed during the current study are available from the corresponding author on reasonable request.

Ethics approval and consent to participate

The study was approved by Hamad Medical Corporation Medical Research Centre and Institutional Review Board in Qatar on Aug 18, 2019, approval reference MRC-04-19-232.

\section{Consent for publication}

A written informed consent for publishing patient's information and images was obtained from the patient.

\section{Competing interests}

The authors declare that they have no competing interests.

\section{Author details}

${ }^{1}$ Pharmacy Department, Heart Hospital, Hamad Medical Corporation, P.O. Box 3050, Doha, Qatar. 'Internal Medicine Department, Hamad General Hospital, 
Hamad Medical Corporation, Doha, Qatar. ${ }^{3}$ Cardiology and Cardiovascular Surgery Department, Heart Hospital, Hamad Medical Corporation, Doha, Qatar.

Received: 10 January 2020 Accepted: 1 April 2020

Published online: 19 April 2020

\section{References}

1. Tanis BC, Rosendaal FR. Venous and arterial thrombosis during Oral contraceptive use: risks and risk factors. Semin Vasc Med. 2003;3(1):69-84.

2. Speroff L, Darney PH. A Clinical Guide for Contraception. 5th Edition. Wolters Kluwer, 2011.

3. Godsland IF, Crook D, Simpson R, et al. The effects of different formulations of oral contraceptive agents on lipid and carbohydrate metabolism. N Engl J Med. 1990:323(20):1375-81.

4. Bringer J. Norgestimate: a clinical overview of a new progestin. Am J Obstet Gynecol. 1992;166(6 Pt 2):1969-77.

5. Badimon L, Bayés-Genís A. Effects of progestogens on thrombosis and atherosclerosis. Hum Reprod Update. 1999;5(3):191-9.

6. Roach RE, Helmerhorst FM, Lijfering WM, Stijnen T, Algra A, Dekkers OM. Combined oral contraceptives: the risk of myocardial infarction and ischemic stroke. Cochrane Database Syst Rev. 2015:8:CD011054.

7. Van Den Bosch MA, Kemmeren JM, Tanis BC, et al. The RATIO study: oral contraceptives and the risk of peripheral arterial disease in young women. J Thromb Haemost. 2003;1(3):439-44.

8. Thorneycroft $\mid \mathrm{H}$. Oral contraceptives and myocardial infarction. Am J Obstet Gynecol. 1990;163(4 Pt 2):1393-7.

9. Tchaikovski SN, Rosing J. Mechanisms of estrogen induced venous thromboembolism. Thromb Res. 2010;126(1):5-11.

10. Ouyang P, Michos ED, Karas RH. Hormone replacement therapy and the cardiovascular system lessons learned and unan $\neg$ swered questions. J Am Coll Cardiol. 2006;47:1741-53.

11. Aslan AN, Süygün H, Sivri S, Keleş T. Low-dose oral contraceptive-induced acute myocardial infarction. Eur J Contracept Reprod Health Care. 2016; 21(6):499-501.

\section{Publisher's Note}

Springer Nature remains neutral with regard to jurisdictional claims in published maps and institutional affiliations.

Ready to submit your research? Choose BMC and benefit from:

- fast, convenient online submission

- thorough peer review by experienced researchers in your field

- rapid publication on acceptance

- support for research data, including large and complex data types

- gold Open Access which fosters wider collaboration and increased citations

- maximum visibility for your research: over $100 \mathrm{M}$ website views per year

At $\mathrm{BMC}$, research is always in progress.

Learn more biomedcentral.com/submissions 